\title{
Needle-shaped electrode for speciation analysis of copper in seawater
}

\author{
Haitao Han ${ }^{\text {a, b, } 1}$, Wenyan Tao ${ }^{\text {c, } 1}$, Xueping Hu ${ }^{\text {a, b, } 1}$, Xiaoyan Ding ${ }^{\text {a, b }}$, Dawei Pan ${ }^{\text {a, b, * }}$, \\ Chenchen Wang ${ }^{a}$, Shuhua $\mathrm{Xu}^{\mathrm{d}}$ \\ ${ }^{a}$ CAS Key Laboratory of Coastal Environmental Processes and Ecological Remediation, Research Center for Coastal Environment Engineering Technology of \\ Shandong Province, Yantai Institute of Coastal Zone Research, Chinese Academy of Sciences, Yantai, 264003, PR China \\ b University of Chinese Academy of Sciences, Beijing, 100049, PR China \\ c Shenzhen Huachenyang Technology Company, Shenzhen, 510081, PR China \\ ${ }^{\mathrm{d}}$ Yantai Environmental Monitoring Center, Yantai, 264010, PR China
}

\section{A R T I C L E I N F O}

\section{Article history:}

Received 14 June 2018

Received in revised form

23 August 2018

Accepted 26 August 2018

Available online 14 September 2018

\section{Keywords:}

Needle-shaped electrode

Dendritic gold nanostructures

Ion-exchange polymer

Copper speciation

Seawater

\begin{abstract}
A B S T R A C T
Here, a needle-shaped electrode based on commercial acupuncture needle was fabricated and functionalized with dendritic gold nanostructures (AuNDs) and ion-exchange polymer (Nafion) for voltammetric speciation analysis of copper $(\mathrm{Cu})$ in seawater. To achieve the enhanced performance for voltammetric determination of $\mathrm{Cu}$ in seawater, the acupuncture needle electrode (ANE) was functionalized with AuNDs via electrochemical deposition and covered with Nafion. AuNDs facilitate the electrochemical responses of $\mathrm{Cu}$ due to their excellent catalytic and electroconductive properties, whereas Nafion can stabilize the AuNDs deposited on the surface of the needle tip and enhance the voltammetric responses through its specific cation-exchange ability with $\mathrm{Cu}^{2+}$. The so-designed AuNDs/Nafion/ANE showed excellent performance for the determination of $\mathrm{Cu}$ in complex matrix like seawater. Under the optimal conditions, the response of $\mathrm{Cu}$ at this functional needle-shaped electrode was linear in the concentration range from 0.05 to $1 \mathrm{nmol} \mathrm{L}^{-1}$ with an ultralow detection limit of $15.4 \mathrm{pmol} \mathrm{L}^{-1}$. Additionally, the functional needle-shaped electrode has been successfully used for the direct determination of different $\mathrm{Cu}$ species in seawater via anodic stripping voltammetry.
\end{abstract}

() 2018 Elsevier Ltd. All rights reserved.

\section{Introduction}

In the past decades, global economic and industrial developments have resulted in a large number of pollutants to be dumped into the marine environment, which led to an increased concern for both public and environmental health [1]. The marine ecosystems are becoming increasingly degraded due to the anthropogenic inputs of heavy metals, such as copper $(\mathrm{Cu})$, cadmium $(\mathrm{Cd})$, and lead $(\mathrm{Pb})[2,3]$. Although $\mathrm{Cu}$ is a trace element indispensable for maintaining seawater biological activities, an excess amount of bioavailable $\mathrm{Cu}$ is toxic [4,5]. Indeed, $\mathrm{Cu}$ not only has a high impact in the heavy-metal toxicity issues in the marine organisms, but also threatens human health by bioaccumulation [6].

\footnotetext{
* Corresponding author. CAS Key Laboratory of Coastal Environmental Processes and Ecological Remediation, Research Center for Coastal Environment Engineering Technology of Shandong Province, Yantai Institute of Coastal Zone Research, Chinese Academy of Sciences, Yantai, 264003, PR China.

E-mail address: dwpan@yic.ac.cn (D. Pan).

1 These authors contributed equally to this work.
}

Therefore, the effect of $\mathrm{Cu}$ in the marine environment has received considerable attention because of its dangerous consequences on the ecosystem and human health. $\mathrm{Cu}$ also plays a crucial role in promoting plankton growth and regulating biogeochemical processes [7]. However, the total concentration of $\mathrm{Cu}$ is not a parameter sufficient to efficiently assess its bioavailability, behavior, and toxicity [8]; indeed, the relevance of $\mathrm{Cu}$ for the environment does not depend on its concentration but on its aqueous speciation. Therefore, to further study the ecological function, biological impact, and toxic metabolism of $\mathrm{Cu}$, it is essential to determine the occurrence and relative abundance of different $\mathrm{Cu}$ species in seawater. So speciation-selective analytical methods should be developed to achieve the speciation analysis of $\mathrm{Cu}$.

Several methods have been used to conduct the speciation analysis of $\mathrm{Cu}$ and other metal elements in seawater. A conventional approach for determining the species of metals like $\mathrm{Cu}$ combines the separation techniques (including gas chromatography [9], supercritical-fluid chromatography [10], and capillary zone electrophoresis [11]) with detection methods (including atomic absorption spectrometry [12], atomic emission spectrometry [13], 
atomic fluorescence spectrometry [14], and inductively coupled plasma mass spectrometry [15]). Although these methods have many advantages, a significant limitation is their requirement for a series of elaborate pre-treatments, which are time and work expensive. In other words, there is an urgent need to develop more effective and simple methods to conduct the speciation analysis of $\mathrm{Cu}$ and other metals.

Anodic stripping voltammetry (ASV) is an efficient and simple electroanalytical technique for speciation analysis due to its high selectivity and sensitivity, excellent performance with saline matrices, such as seawater, as well as the rapid and straightforward analytical processes required [16]. Annibaldi et al. surveyed the total and dissolved $\mathrm{Cu}, \mathrm{Pb}, \mathrm{Cd}$ in the estuary and coastal systems of Italy via square wave anodic stripping voltammetry (SWASV) $[17,18]$. The mercury electrode has frequently been used as the working electrode for the speciation analysis of $\mathrm{Cu}$ and other metals due to its high sensitivity and stability [17-20]. However, the mercury electrode has significant drawbacks including toxicity and difficulties in handling process [21]. Although several chemicallymodified electrodes have been developed to replace the mercury electrode, most of them cannot be applied to the determination of dissolved active $\mathrm{Cu}$, one of the $\mathrm{Cu}$ species, because of its relatively low concentration in seawater [6]. Therefore, there is a compelling need to fabricate an ultrasensitive electrode for the direct determination of $\mathrm{Cu}$ species in seawater.

Acupuncture needle is a new emerging substrate material for constructing highly sensitive electrodes. Acupuncture is a traditional Chinese technique for relieving pain and performing disease therapies by inserting and manipulating acupuncture needles into the body acupuncture points (or acupoints) [22]. Among multiple acupuncture needles, the stainless steel needle is quite cheap, easy to handle [23]. It has been reported that it is possible to manufacture the acupuncture needle as a needle-shaped electrode for electrochemical and bio-sensing applications [24,25]. Because of the low price, the needle-shaped acupuncture needle electrode (ANE) can be used disposably with no extra polishing process before electrochemical experiments. More importantly, the unique needle-shaped structure provides larger specific surface area for the modification of functional nanomaterials. Thanks to the unique shape and size, the ANE modified with functional nanomaterials can exhibit much superior performance in sensitivity and detection limit than the conventional electrodes. Gold nanomaterials, especially those with dendritic structures, possess plenty of interesting electrochemical properties, such as large surface-to-volume ratio, high conductivity, and excellent electrocatalytic performance, which make them optimal candidates for electrode modification [26]. Moreover, gold nanomaterials are provided with an outstanding catalytic performance for the electrochemical detection of $\mathrm{Cu}^{2+}$ and other targets $[6,27,28]$. Nafion, one of the most widely used cation-exchange polymers, can form a thin film on the surface of nanomaterials and stabilize them due to its high chemical and mechanical stability. Furthermore, Nafion has the remarkable effect in pre-concentrating cation targets based on its excellent ion-exchange capability, which make it widely used in the electrochemical analytical field [29].

This work combined the unique needle-shaped structure and micro-size of ANE with the excellent electrochemical properties of dendritic gold nanostructures (AuNDs) and specific preconcentration ability of Nafion to fabricate a functional needleshaped electrode with enhanced performance for the analysis of $\mathrm{Cu}$ in seawater. Indeed, an AuNDs/Nafion functionalized ANE (AuNDs/Nafion/ANE) with remarkably improved sensitivity for the voltammetric determination of $\mathrm{Cu}^{2+}$ have been designed. The schematic of determination of $\mathrm{Cu}^{2+}$ on the so-designed functional needle-shaped electrode can be explained as the adsorption- catalysis model. The experimental conditions and analytical performance of the AuNDs/Nafion/ANE have been systematically assessed. To achieve the speciation analysis of $\mathrm{Cu}$, the dissolved active, dissolved acid extractable, and total acid extractable $\mathrm{Cu}$ in seawater were all successfully determined with the functional needle-shaped electrode via anodic stripping voltammetry with excellent results.

\section{Experimental}

\subsection{Reagents and materials}

All the reagents were analytical-grade chemicals and used without further purification. The stock standard solution of $1000 \mathrm{mg} \mathrm{L}^{-1} \mathrm{Cu}$ was supplied by the National Research Centre for Certified Reference Materials (CRMs), Beijing, China. Separate standard solutions were prepared by dilution of the stock solution with $10 \%(\mathrm{v} / \mathrm{v}) \mathrm{HNO}_{3}$ to the specific concentration required. $\mathrm{HAuCl}_{4} \cdot 4 \mathrm{H}_{2} \mathrm{O}$ was purchased from Sinopharm Chemical Reagent Co. Ltd., and $2 \mathrm{mmol} \mathrm{L}^{-1} \mathrm{HAuCl}_{4}$ solution was prepared in $0.5 \mathrm{~mol} \mathrm{~L}^{-1} \mathrm{H}_{2} \mathrm{SO}_{4}$ for electrodeposition. Nafion (5 wt\% in a mixture of lower aliphatic alcohols and water, contains $45 \%$ water) was purchased from Sigma-Aldrich Co. Ltd. Acetate buffer solution ( $\mathrm{pH}$ 4.5) was prepared by $0.1 \mathrm{~mol} \mathrm{~L}^{-1}$ acetic acid and $0.1 \mathrm{~mol} \mathrm{~L}^{-1}$ sodium acetate. Deionized water ( $18.2 \mathrm{M} \Omega \mathrm{cm}$ specific resistance) obtained with a Pall Cascada laboratory water system was used throughout.

Stainless steel acupuncture needles (Size $0.25 \times 60 \mathrm{~mm}$, Lot No. 160082) were purchased from Suzhou Medical Appliance Factory Co. Ltd. (Suzhou, China). PVC tubes were obtained by removing the internal copper from the copper electric wires. Silicone rubber (NANDA no. 704) was purchased from Liyang Kangda Chemical Co. Ltd., China.

\subsection{Apparatus}

The morphologies of the bare and modified ANEs were characterized via scanning electron microscopy (SEM, Hitachi S-4800 microscope, Japan). Electrochemical Work Station (CHI 660E, Shanghai CHI Instruments, China) was used throughout all the electrochemical experiments. The modified ANE served as the working electrode, with $\mathrm{Ag} / \mathrm{AgCl}\left(3.0 \mathrm{~mol} \mathrm{~L}^{-1} \mathrm{KCl}\right)$ and platinum foil serving as the reference and counter electrodes, respectively. All potentials were measured with respect to the $\mathrm{Ag} / \mathrm{AgCl}$ reference electrode.

\subsection{Preparation of the AuNDs/Nafion/ANE}

The procedure for the fabrication of the AuNDs/Nafion/ANE was illustrated in Scheme 1. Firstly, PVC tube was cut to a proper length to insulate the acupuncture needle. The acupuncture needle was, thus, inserted into the PVC tube with the needle tip outside about $3 \mathrm{~mm}$ for sensing surface and needle handle outside for connecting with Electrochemical Work Station. Then, the two openings of the PVC tube were sealed with silicone rubber, and the sensing tip of the needle was controlled about $2 \mathrm{~mm}$ length. After the silicone rubber was solidification at room temperature, the ANE was fabricated.

Before modification, the ANE was treated with an ultrasonic cleaning process by using water and ethanol for $5 \mathrm{~min}$. The formation of AuNDs on ANE surface was achieved by electrodepositing in $2 \mathrm{mmol} \mathrm{L}^{-1} \mathrm{HAuCl}_{4}$ solution at the deposition potential of $-0.3 \mathrm{~V}$ for $120 \mathrm{~s}$. Then, the sensing tip of the AuNDs modified ANE (AuNDs/ ANE) was immersed in $2.5 \mathrm{wt} \%$ Nafion solution for $1-3 \mathrm{~s}$ to cover the Nafion film on the surface of AuNDs. It was found that the immerse time had little effect on the electrochemical response of $\mathrm{Cu}$ if the concentration of Nafion was constant (Fig. S1). Eventually, the AuNDs/Nafion/ANE was obtained after the electrode was dried 


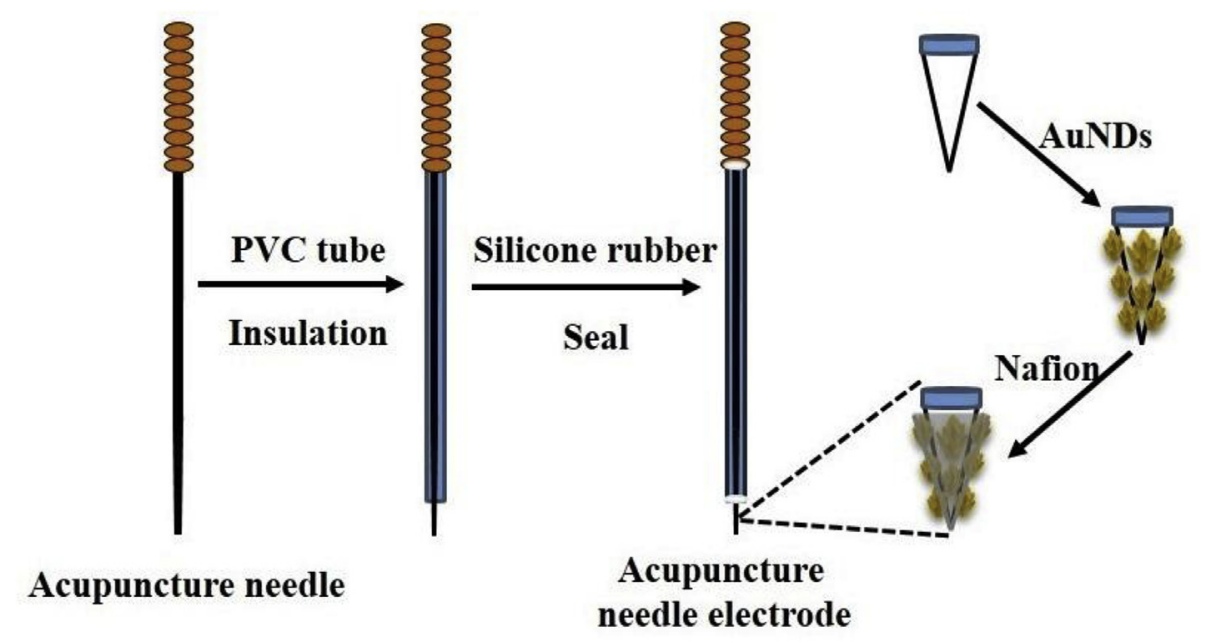

Scheme 1. Schematic diagram for the fabrication of AuNDs/Nafion/ANE.

at room temperature.

\subsection{Preparation of seawater samples}

Seawater samples were collected from three different locations across the Sishili Bay, Northern Yellow Sea, China in November 2017. A 2.5 L sample collector was used to collect seawater into polypropylene containers, which were washed with a solution of $1 \mathrm{~mol} \mathrm{~L}^{-1} \mathrm{HCL}$ and rinsed with deionized water. All the apparatus used were also appropriately cleaned with $\mathrm{HNO}_{3}$, and then thoroughly washed using deionized water before starting the experiments. Seawater samples were immediately processed after collection, as summarized in Fig. S2. Each sample was divided into three aliquots; the first was filtered $(0.45 \mu \mathrm{m}$ membrane filters $)$ and kept in a refrigerator at $4{ }^{\circ} \mathrm{C}$ to determine the dissolved active $\mathrm{Cu}$ concentration. The second aliquot was filtered, acidified with ultrapure $\mathrm{HCl}(\mathrm{pH} \mathrm{1.8)}$ for $48 \mathrm{~h}$, and kept in the refrigerator to determine the dissolved acid extractable $\mathrm{Cu}$ concentration. The last aliquot was acidified for $48 \mathrm{~h}$, filtered, and kept to determine the total acid extractable $\mathrm{Cu}$ concentration. The dissolved active, dissolved acid extractable, and total acid extractable $\mathrm{Cu}$ concentrations were determined directly with the AuNDs/Nafion/ANE by using the standard addition method without any pre-concentrations and additional reagent.

\subsection{Electrochemical analysis procedure}

Unless otherwise stated, the experiments were performed in seawater samples after corresponding pre-treatments. The first step of the ASV analysis was the accumulation step, during which the deposition potential and deposition time were determined for $\mathrm{Cu}:-0.3 \mathrm{~V}$ and $120 \mathrm{~s}$, respectively. After the accumulation step and an equilibration period of $10 \mathrm{~s}$, SWASV was performed from 0.1 to $0.5 \mathrm{~V}(0-0.5 \mathrm{~V}$ for the calibration curve comparatively) by using the following parameters: initial potential of $0.1 \mathrm{~V}$, final potential of $0.5 \mathrm{~V}$, amplitude of $0.025 \mathrm{~V}$, potential incremental of $0.004 \mathrm{~V}$, frequency of $25 \mathrm{~Hz}$, and quiet time of $2 \mathrm{~s}$. Before the next measurement, the electrode was cleaned for $40 \mathrm{~s}$ at $0.4 \mathrm{~V}$ with stirring.

\section{Results and discussion}

\subsection{Characterization of the AuNDs/Nafion/ANE}

Fig. 1 displays the SEM images of the fabricated ANE before and after nanomaterials modification. As shown in Fig. $1 \mathrm{~A}$ and $\mathrm{B}$, the bare ANE has a smooth surface with the tip diameter around $5 \mu \mathrm{m}$. AuNDs are distributed uniformly on the surface of ANE after the process of electrochemical deposition (Fig. 1C). These AuNDs are made up of few gold nanobranches with the top width of $40-60 \mathrm{~nm}$ and length of $250-400 \mathrm{~nm}$. As to the AuNDs/Nafion/ ANE, it can be seen clearly that there is a film covers on the surface of AuNDs after the modification of Nafion (Fig. 1D). The covered Nafion acts as the bridging agent which can connects the AuNDs each other to form the larger dendritic structures, and also acts as the fixing agent which can fix the deposited AuNDs on the tip surface tightly. The results of SEM characterization demonstrate that both AuNDs and Nafion have been successfully modified to the ANE as anticipated. Furthermore, the unique needle-shaped structure of ANE, excellent electrocatalytic ability of AuNDs, and outstanding adsorption ability of Nafion can contribute to the improved detection performance for $\mathrm{Cu}^{2+}$.

The electrochemical properties of the AuNDs/Nafion/ANE were further investigated via cyclic voltammetry. The cyclic voltammograms of the bare ANE, AuNDs/ANE, and AuNDs/Nafion/ANE in $0.1 \mathrm{~mol} \mathrm{~L}^{-1}$ acetate buffer solutions from 0.2 to $1.3 \mathrm{~V}$ have been recorded to characterize the gold nanomaterials modified on the electrodes (Fig. 2A). No redox peak could be observed in the voltammogram of bare ANE, whereas a sharp reduction peak at $0.62 \mathrm{~V}$ and an oxidation peak at $1.0 \mathrm{~V}$ caused by the redox of AuNDs can be observed for AuNDs/ANE. Interestingly, after the modification of Nafion on the surface of AuNDs/ANE, the typical reduction peak of AuNDs becomes smaller. The cyclic voltammograms of these three electrodes in acetate buffer from $-0.2-0.6 \mathrm{~V}$ have also been conducted (Fig. 2B). It can be seen that the background current of AuNDs/ANE is considerably larger than that of the bare ANE. However, similar to typical peak of AuNDs, the background current of AuNDs/Nafion/ANE is smaller than that of AuNDs/ANE. It can be concluded that the background current enhancement of AuNDs/ ANE is due to the excellent ability of AuNDs in facilitating electron transfer. For the AuNDs/Nafion/ANE, the decrease of the typical peak current and background current might be ascribed to the relatively weak electron transfer capability (electro-conductivity) of Nafion.

To verify the capability of electron transfer of different electrodes, as well as the combined effects of AuNDs and Nafion, electrochemical impedance spectrum (EIS) was conducted. The semicircle at the high frequency of EIS indicates an electrontransfer-limited process on the electroactive surface. So the 

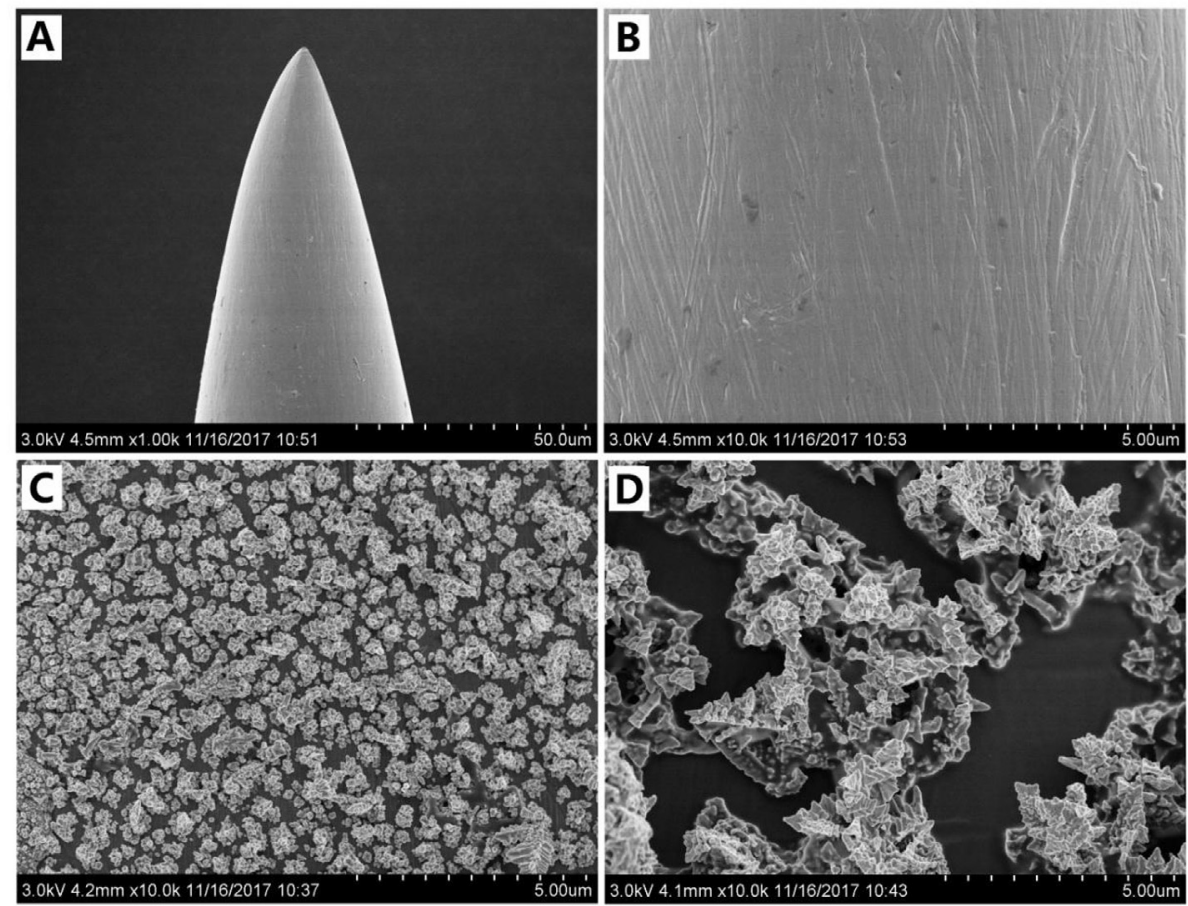

Fig. 1. SEM images of the so-fabricated ANE (A, B), AuNDs/ANE (C), and AuNDs/Nafion/ANE (D).
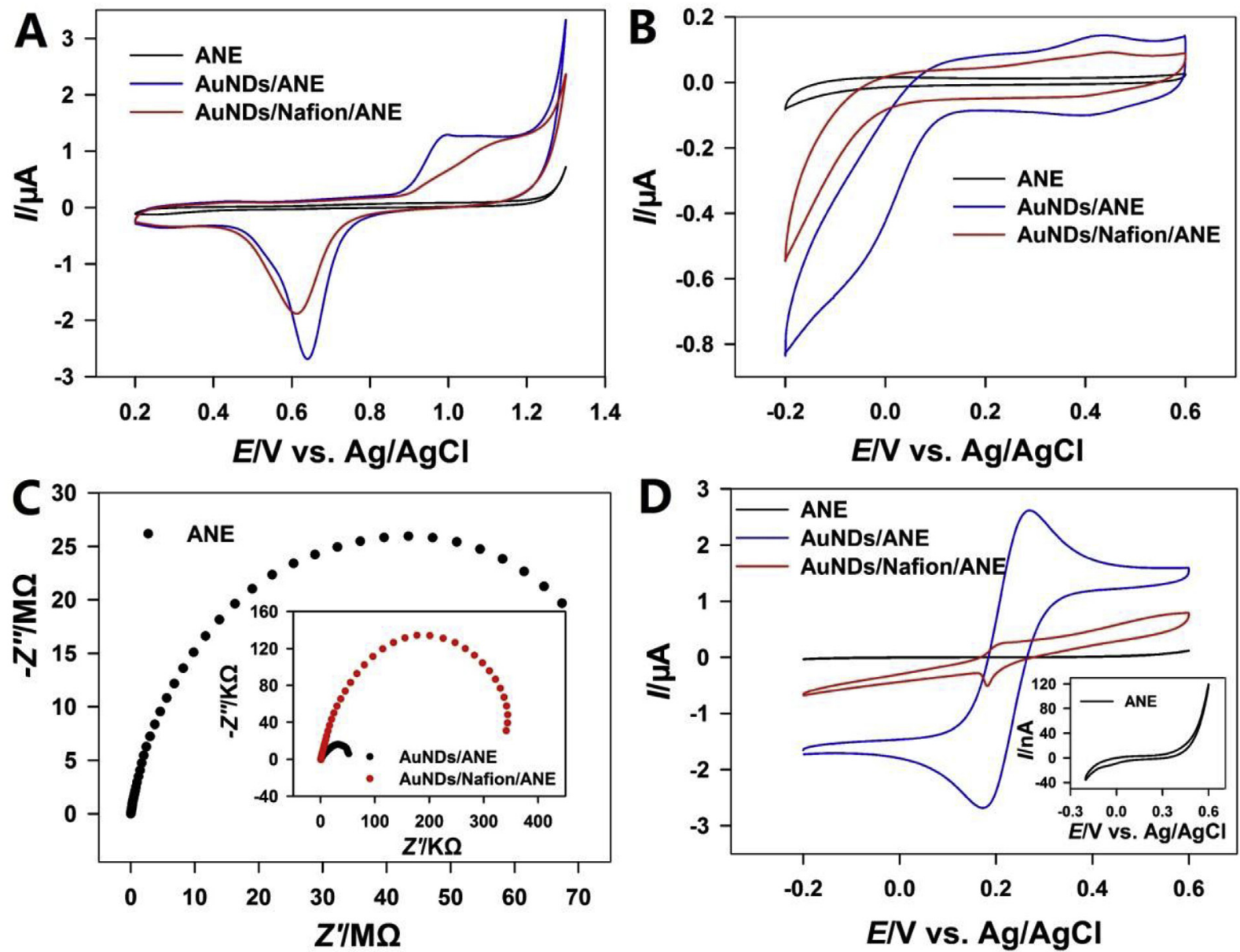

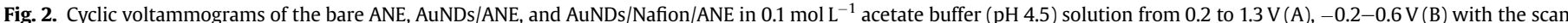

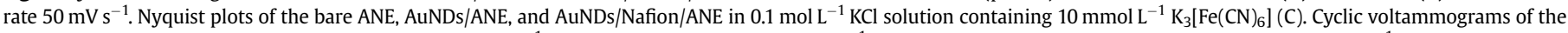
bare ANE, AuNDs/ANE, and AuNDs/Nafion/ANE in $0.1 \mathrm{~mol} \mathrm{~L}^{-1} \mathrm{KCl}$ solution containing $10 \mathrm{mmol} \mathrm{L}^{-1} \mathrm{~K}_{3}\left[\mathrm{Fe}(\mathrm{CN})_{6}\right]$ from $-0.2-0.6 \mathrm{~V}$ with a scan rate of $25 \mathrm{mV} \mathrm{s}{ }^{-1}(\mathrm{D})$. 
electron transfer resistance (Ret) of the electroactive surface can be measured by the semicircle diameter at high frequency. As shown in Fig. 2C, the Nyquist diagrams of bare ANE, AuNDs/ANE, and AuNDs/Nafion/ANE were measured in $10 \mathrm{mmol} \mathrm{L}^{-1} \mathrm{~K}_{3}\left[\mathrm{Fe}(\mathrm{CN})_{6}\right]$ solution with $0.1 \mathrm{~mol} \mathrm{~L}^{-1} \mathrm{KCl}$. By comparing the semicircle diameters of different electrodes, it can be observed that the Ret of AuNDs/ANE is significantly smaller than that of bare ANE. This phenomenon is due to the excellent ability of AuNDs in facilitating electron transfer which promotes the $\left[\mathrm{Fe}(\mathrm{CN})_{6}\right]^{3-} /\left[\mathrm{Fe}(\mathrm{CN})_{6}\right]^{4-}$ redox process. However, the Ret becomes larger after the modification of Nafion on the surface of AuNDs/ANE, which indicates the relatively weak electro-conductivity of Nafion and the inhibition effect between negatively-charged Nafion and $\left[\mathrm{Fe}(\mathrm{CN})_{6}\right]^{3-}$ / $\left[\mathrm{Fe}(\mathrm{CN})_{6}\right]^{4-}$ probe. These results demonstrate that the AuNDs/ Nafion/ANE could be successfully fabricated, and AuNDs have the excellent ability in facilitating electron transfer, while Nafion has relatively weak electro-conductivity. It should be noted that despite its relatively weak electro-conductivity, Nafion can facilitate the adsorption and pre-concentration of $\mathrm{Cu}^{2+}$ due to its outstanding cation-exchange ability.

$\left[\mathrm{Fe}(\mathrm{CN})_{6}\right]^{3-} /\left[\mathrm{Fe}(\mathrm{CN})_{6}\right]^{4-}$ redox couple has also been commonly used as the electrochemical probe to calculate the electroactive surface areas and study the properties of modified electrodes. Fig. 2D shows the cyclic voltammograms of the bare ANE, AuNDs/ANE, and AuNDs/Nafion/ANE using $\left[\mathrm{Fe}(\mathrm{CN})_{6}\right]^{3-} /\left[\mathrm{Fe}(\mathrm{CN})_{6}\right]^{4-}$ redox couple as an electrochemical probe. Almost no redox peak can be observed in the voltammogram of bare ANE, whereas the AuNDs/ANE shows the highest current response. The visible symmetrical redox reaction of $\mathrm{K}_{3}\left[\mathrm{Fe}(\mathrm{CN})_{6}\right]$ on the AuNDs/ANE was proven as a reversible process. The relatively weak electro-conductivity of Nafion might be presented as an obvious explanation for the current decrease of AuNDs/ Nafion/ANE. Moreover, Nafion is negatively charged and could hinder the electron transfer between the probe and electrode, which would also decreases the current response. Considering that no other free ions were added in the $\left[\mathrm{Fe}(\mathrm{CN})_{6}\right]^{3-} /\left[\mathrm{Fe}(\mathrm{CN})_{6}\right]^{4-}$ solution, the difference between reduction and oxidation peak on intensity and shape might be resulted from the hindrance role of Nafion. The electroactive surface areas of the modified electrodes were estimated according to the Randles-Sevcik equation:

Ip $=2.69 \times 10^{5} n^{3 / 2} \mathrm{~A} \mathrm{D}^{1 / 2} v^{1 / 2} c_{0}$

where $I p$ is the anodic peak current, $n$ is the electron transfer number, $A$ is the electroactive surface area of the electrode, $D$ is the diffusion coefficient, $v$ is the scan rate, and $c_{0}$ is the concentration of $\mathrm{K}_{3}\left[\mathrm{Fe}(\mathrm{CN})_{6}\right]$. For $10 \mathrm{mmol} \mathrm{L}^{-1} \mathrm{~K}_{3}\left[\mathrm{Fe}(\mathrm{CN})_{6}\right]$ in $0.1 \mathrm{~mol} \mathrm{~L}^{-1} \mathrm{KCl}$ electrolyte, $n$ is 1 and $\mathrm{D}$ is $7.6 \times 10^{-6} \mathrm{~cm}^{2} \mathrm{~s}^{-1}$. The active surface areas could be calculated from the slope of the $I p$ versus $v^{1 / 2}$, which was shown in Fig. S3. Five different scan rates $(10,25,50,75$, and $100 \mathrm{mV} \mathrm{s}^{-1}$ ) were used to set up the calibration curves for determination of electroactive surface areas. Thus, the electroactive surface areas of bare ANE, AuNDs/ANE, and AuNDs/Nafion/ANE were $2.35 \times 10^{-6}, 3.36 \times 10^{-3}$ and $1.93 \times 10^{-4} \mathrm{~cm}^{2}$, respectively. The results show that the presence of AuNDs can increase the electroactive surface significantly compared with the bare ANE. Although the existence of Nafion decreases the electroactive surface area due to its relatively weak electro-conductivity and inhibition effect, it can enhance the electrochemical response of $\mathrm{Cu}^{2+}$ due to its excellent ability in adsorption and pre-concentration.

\subsection{Mechanism of $\mathrm{Cu}^{2+}$ determination on the AuNDs/Nafion/ANE}

SWASV responses of bare ANE, AuNDs/ANE and AuNDs/Nafion/ ANE to $50 \mathrm{nmol} \mathrm{L}^{-1} \mathrm{Cu}^{2+}$ in $0.1 \mathrm{~mol} \mathrm{~L}^{-1}$ acetate buffer supporting electrolyte were shown in Fig. 3. No anodic signal can be detected

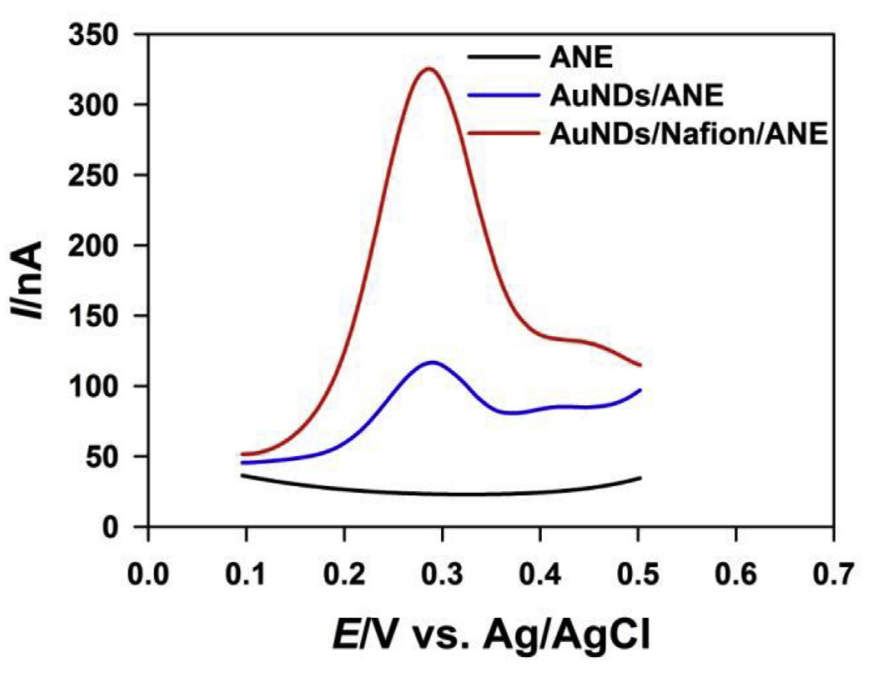

Fig. 3. Square wave voltammograms of the bare ANE, AuNDs/ANE, and AuNDs/Nafion/ ANE in $0.1 \mathrm{~mol} \mathrm{~L}^{-1}$ acetate buffer $(\mathrm{pH} 4.5)$ solution containing $50 \mathrm{nmol} \mathrm{L}^{-1} \mathrm{Cu}^{2+}$.

for the bare ANE with $50 \mathrm{nmol} \mathrm{L}^{-1} \mathrm{Cu}^{2+}$, while an oxidation peak at about $0.3 \mathrm{~V}$ can be observed for the AuNDs/ANE due to the excellent electrochemical performance of AuNDs. As expected, the current response of AuNDs/Nafion/ANE is much larger than that of AuNDs/ ANE. There is no doubt that AuNDs/Nafion/ANE shows the best performance for $\mathrm{Cu}^{2+}$ detection after the combination of AuNDs and Nafion. To explain the superior performance of AuNDs/Nafion/ ANE, mechanism of $\mathrm{Cu}^{2+}$ determination on the electrode has been investigated.

For anodic stripping voltammetric analysis, it is very important for the effective adsorption of target on the electrode surface. At this stage, a large amount of $\mathrm{Cu}^{2+}$ will be pre-concentrated on the surface of Nafion due to its outstanding adsorption ability through ion-exchange reaction. And after the adsorption of $\mathrm{Cu}^{2+}$, the AuNDs on the surface of ANE will serve as the electrochemical reaction interfaces. On the interfaces, the reactions of $\mathrm{Cu}^{2+}$ reduced to $\mathrm{Cu}^{0}$ during the accumulation process, and $\mathrm{Cu}^{0}$ oxidised to $\mathrm{Cu}^{2+}$ during the stripping process will take place. It is well known that the AuNDs have superior properties in facilitating electron transfer and excellent catalytic performance for electrochemical detection. Despite Nafion could decrease the current response due to its relatively weak electro-conductivity, it enhances the detection performance by facilitating the cation-exchange reaction for the pre-concentration of $\mathrm{Cu}^{2+}$. Therefore, in the competition between the two effects provided by Nafion, the pre-concentration effect dominated in the voltammetric detection of $\mathrm{Cu}^{2+}$. So the improved electrochemical response of the AuNDs/Nafion/ANE for $\mathrm{Cu}^{2+}$ could be explained as a combined effects of the adsorption ability of Nafion and excellent electrocatalytic ability of AuNDs [30,31]. The schematic of voltammetric detection of $\mathrm{Cu}^{2+}$ on the AuNDs/Nafion/ ANE based on the adsorption-catalysis model was shown in Scheme 2.

\subsection{Optimization for the response of $\mathrm{Cu}$ on the AuNDs/Nafion/ANE}

The deposition time of the AuNDs at ANE surface was investigated ranging from 30 to $210 \mathrm{~s}$. As shown in Fig. 4A, the anodic peak current (Ip) gradually increases from 30 to $120 \mathrm{~s}$ and, then, remains almost constant from 120 to $210 \mathrm{~s}$. The maximum Ip is at the deposition time from 120 to $210 \mathrm{~s}$. It has been illustrated that AuNDs increase the electroactive surface area significantly and show excellent catalytic performance for the electrochemical 


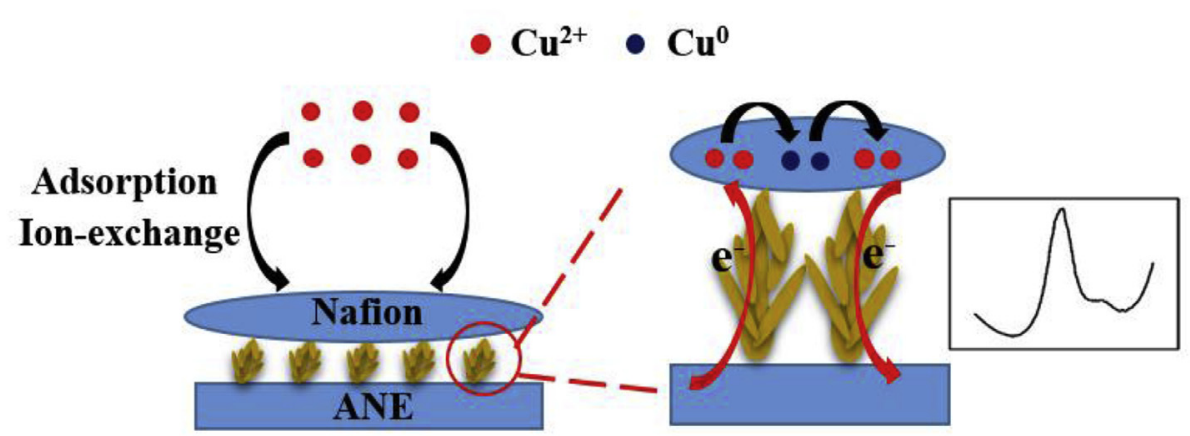

Scheme 2. Schematic of voltammetric determination of $\mathrm{Cu}^{2+}$ on AuNDs/Nafion/ANE based on the adsorption of Nafion and the fast electron transfer of AuNDs.

detection of $\mathrm{Cu}^{2+}$. At the first $120 \mathrm{~s}$ of the deposition time, more AuNDs will be deposited on the surface of ANE and provide more electroactive sites for $\mathrm{Cu}^{2+}$ detection. As a result, the Ip gradually increases with the deposition time at this stage. However, when the deposition time is more than 120s, the electroactive surface area will not increase continually due to the aggregation of AuNDs, and sequentially no enhancement of Ip obtained. Therefore, $120 \mathrm{~s}$ was selected as the optimal time for the deposition of AuNDs.

The effect of the amount of Nafion on the AuNDs/ANE surface could be investigated at the concentrations ranging from $0.1 \%$ to $5 \%$ (Fig. 4B). The anodic Ip gradually increases from $0.1 \%$ to $5 \%$ of the
Nafion solution. It should be noted that excess Nafion could hinder the electron transfer between the analyte and modified electrode. However, the decrease of Ip with high concentrations of Nafion has not been observed. The reason might be that only a small quantity of Nafion has been covered on the AuNDs/ANE considering the modification has been conducted via an immersion method. In this work, $2.5 \%$ of the Nafion solution was adopted which was enough for the determination of the dissolved active $\mathrm{Cu}$.

The effect of the accumulation potential on the current response was also investigated with the potential varying from -0.7 to $0.1 \mathrm{~V}$. As shown in Fig. 4C, the maximum Ip can be observed at the
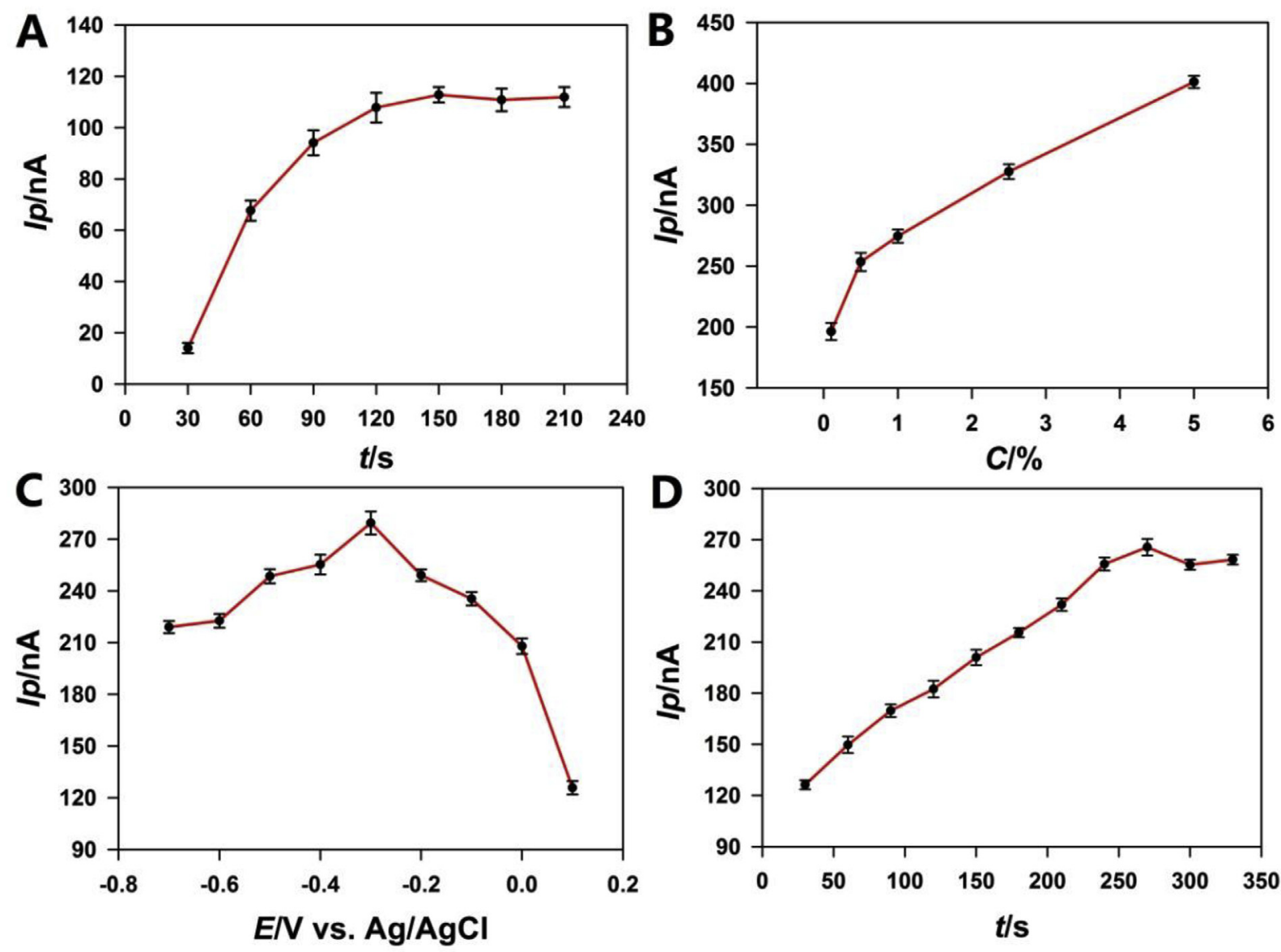

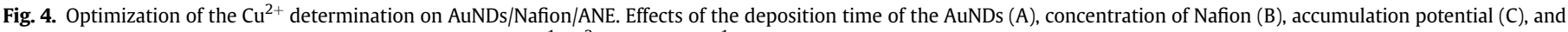
accumulation time (D) on the stripping current of $50 \mathrm{nmol} \mathrm{L}^{-1} \mathrm{Cu}^{2+}$ in $0.1 \mathrm{~mol} \mathrm{~L}^{-1}$ acetate buffer (pH 4.5) solution. 
potential of $-0.3 \mathrm{~V}$. The Ip gradually increases with decreasing potential from 0.1 to $-0.3 \mathrm{~V}$ due to the full reduction of $\mathrm{Cu}^{2+}$ by extremely negative potentials. However, the Ip decreases from -0.3 to $-0.7 \mathrm{~V}$, which is probably caused by the competitive reduction of oxygen. Obviously, the optimum accumulation potential was chosen to be $-0.3 \mathrm{~V}$, and this value has been used in the following measurements.

The influence of the accumulation time on the stripping response was studied in the range from 30 to $330 \mathrm{~s}$ by fixing the deposition potential at $-0.3 \mathrm{~V}$. As shown in Fig. 4D, the Ip increases gradually as the accumulation time increases to $240 \mathrm{~s}$ and then tends to be steady because of the adsorption equilibrium of $\mathrm{Cu}^{2+}$ between the electrode surface and the solution. An accumulation time of $120 \mathrm{~s}$ is enough for carrying out the speciation analysis of $\mathrm{Cu}$. However, higher sensitivity could be obtained by applying an accumulation time longer than $120 \mathrm{~s}$.

\subsection{Analytical performance of the AuNDs/Nafion/ANE for $\mathrm{Cu}$}

Fig. 5 shows the calibration curve and voltammograms obtained at the AuNDs/Nafion/ANE under the optimal conditions, which are

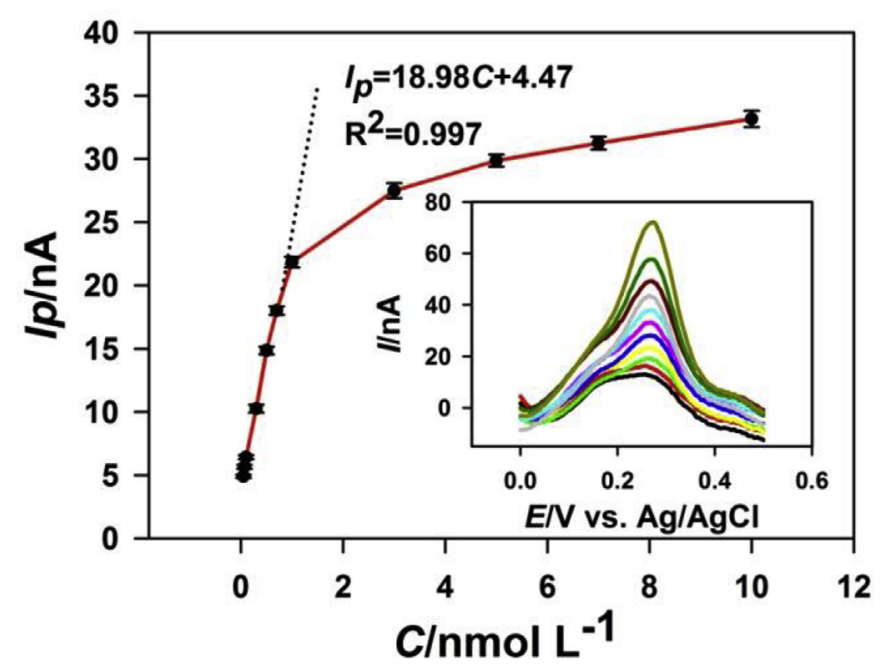

Fig. 5. Calibration curve of $\mathrm{Cu}^{2+}$ at the AuNDs/Nafion/ANE, where the concentrations of $\mathrm{Cu}^{2+}$ are from 0.05 to $10 \mathrm{nmol} \mathrm{L}^{-1}$ in $0.1 \mathrm{~mol} \mathrm{~L}^{-1}$ acetate buffer ( $\mathrm{pH} \mathrm{4.5)}$. Inset shows the voltammograms with baseline correction obtained on the AuNDs/Nafion/ANE with successive addition of $0.05,0.07,0.1,0.3,0.5,0.7,1,3,5,7,10 \mathrm{nmol} \mathrm{L}^{-1} \mathrm{Cu}^{2+}$.
$120 \mathrm{~s}$ of the deposition time, $2.5 \%$ of the Nafion concentration, $-0.3 \mathrm{~V}$ of the accumulation potential, and $120 \mathrm{~s}$ of the accumulation time. The linear regression equation for $\mathrm{Cu}^{2+}$ determination derived from the SWASV curves is $I p=18.98 \mathrm{C}+4.47$ $\left(\mathrm{R}^{2}=0.997\right)$. The Ip is linear when the concentrations of $\mathrm{Cu}^{2+}$ range from 0.05 to $1 \mathrm{nmol} \mathrm{L}^{-1}$. The sensitivity and detection limit of the AuNDs/Nafion/ANE for $\mathrm{Cu}^{2+}$ determination were $18.98 \pm 0.89 \mathrm{nA} /$ nmol L ${ }^{-1}$ and $15.4 \pm 0.7 \mathrm{pmol} \mathrm{L}^{-1}(\mathrm{~s} / \mathrm{n}=3)$, respectively. Additionally, comparison of the proposed method with other analytical approaches for determination of $\mathrm{Cu}^{2+}$ is reported in Table 1 . Compared with other electrodes, the AuNDs/Nafion/ANE provided here has the excellent performance for $\mathrm{Cu}^{2+}$ detection, which is essential to the direct analysis of dissolved active $\mathrm{Cu}$ in seawater. It can be concluded that the AuNDs/Nafion/ANE would be a promising choice for $\mathrm{Cu}^{2+}$ determination in the real seawater samples with higher sensitivity.

\subsection{Reproducibility, repeatability and selectivity}

The repeatability and reproducibility of the newly developed functional needle-shaped electrode were also assessed. The repeatability was evaluated by detecting $50 \mathrm{nmol} \mathrm{L}^{-1} \mathrm{Cu}^{2+}$ at the same electrode for ten measurements and the estimated relative standard deviation (RSD) was $2.9 \%$. The reproducibility of the AuNDs/Nafion/ANE was investigated by six independently modified electrodes prepared in the same method in $50 \mathrm{nmol} \mathrm{L}^{-1} \mathrm{Cu}^{2+}$ and the RSD was $4.9 \%$. Hence, the AuNDs/Nafion/ANE shows good reproducibility and repeatability for the determination of $\mathrm{Cu}^{2+}$. The modified electrode was stored in air condition and tested by determining $\mathrm{Cu}^{2+}$ for five measurements in each day, the current response remained $95.2 \%$ of the initial value after six days, reflecting the excellent stability of the AuNDs/Nafion/ANE.

Additionally, the effects of possible interfering species for $\mathrm{Cu}^{2+}$ determination were investigated by adding foreign species into the $0.1 \mathrm{~mol} \mathrm{~L}^{-1}$ acetate buffer containing $50 \mathrm{nmol} \mathrm{L}^{-1} \mathrm{Cu}^{2+}$ under the optimal working conditions. Square wave voltammograms obtained on the AuNDs/Nafion/ANE for the determination of $\mathrm{Cu}^{2+}$ with typical interfering species $\left(\mathrm{Co}^{2+}\right.$ and $\mathrm{Fe}^{3+}$ ) were showed in Fig. S4. Our results showed that the 100 -fold $\mathrm{K}^{+}, \mathrm{Ca}^{2+}, \mathrm{Mg}^{2+}, \mathrm{Ni}^{2+}$ $\mathrm{Co}^{2+}, \mathrm{Cr}^{3+}, \mathrm{NO}_{3}^{-}, \mathrm{SO}_{4}^{2-}, 50$-fold $\mathrm{Cd}^{2+}, \mathrm{Bi}^{3+}, 40$-fold $\mathrm{Fe}^{3+}, 10$-fold $\mathrm{Pb}^{2+}$ did not affect the determination of $\mathrm{Cu}^{2+}(<5 \%$ of response current change). These findings indicated that the AuNDs/Nafion/ANE had an excellent selectivity for the determination of $\mathrm{Cu}^{2+}$. The excellent selectivity of AuNDs/Nafion/ANE was mainly due to the rapid

Table 1

Comparison of the AuNDs/Nafion/ANE with other analytical approaches for the determination of $\mathrm{Cu}^{2+}$.

\begin{tabular}{|c|c|c|c|c|}
\hline Methods $^{\mathrm{a}}$ & Electrodes $^{\mathrm{b}}$ & Linear range $/ \mathrm{nmol} \mathrm{L}^{-1}$ & Detection limit/nmol L ${ }^{-1}$ & Ref. \\
\hline ED-XRF & No & $800-23000$ & 200 & {$[32]$} \\
\hline FAAS & No & $120-1200$ & 10 & [33] \\
\hline GFAAS & No & $130-700$ & 1.4 & [34] \\
\hline SWASV & $\mathrm{Hg} / \mathrm{MWCNTs} / \mathrm{CHIT} / \mathrm{SPE}$ & $40-200$ & 12 & [35] \\
\hline SWASV & Sn/AuNPs/gold microelectrode & $80-8000$ & 30 & [36] \\
\hline DPASV & $\mathrm{rGO} / \mathrm{Bi} / \mathrm{CPE}$ & $300-1600$ & 400 & [37] \\
\hline DPASV & L-Cys-rGO/GCE & $400-2000$ & 40 & [38] \\
\hline LSSV & CNT/Nafion/GCE & $30-1000$ & 50 & [39] \\
\hline OSWV & Ph-GO/gold electrode & $300-1600$ & 27 & {$[40]$} \\
\hline DPASV & SA/SWNTs/rGO/GCE & $200-2000$ & 6 & [41] \\
\hline DPASV & rGO/AuNP/Nafion/gold electrode & $20-1000$ & 4 & [6] \\
\hline SWASV & Gold microwire electrode & - & 0.025 & [42] \\
\hline SWASV & AuNDs/Nafion/ANE & $0.05-1$ & 0.015 & this work \\
\hline
\end{tabular}

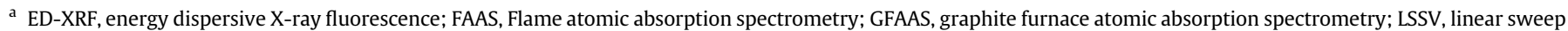
stripping voltammetry; OSWV, Osteryoung square wave voltammetry.

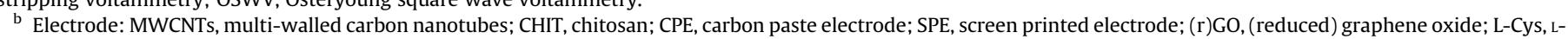
Cysteine; GCE, glassy carbon electrode; CNT, carbon nanotubes; Ph, phenyl group; SA, sodium alginate; SWNTs, single-walled carbon nanotubes. 

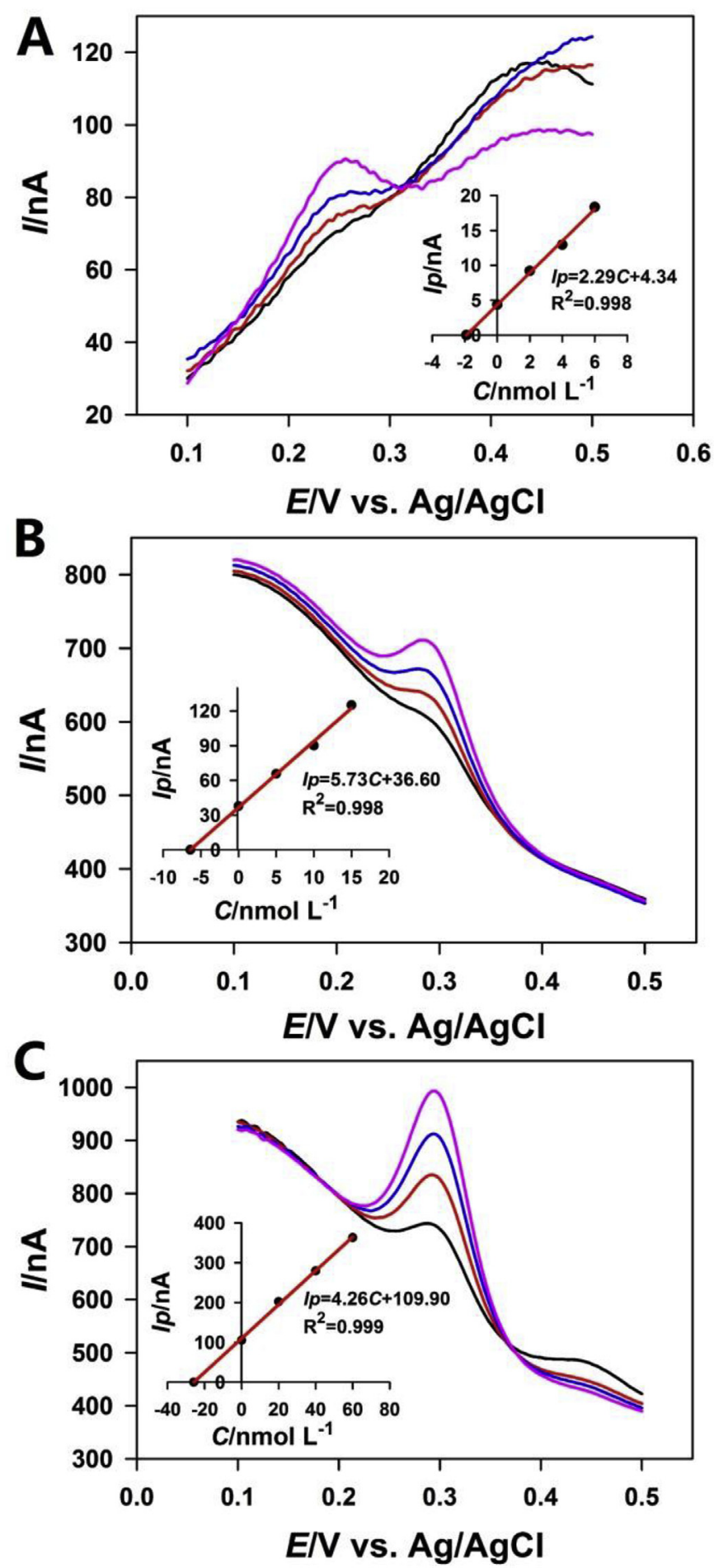

Fig. 6. Voltammetric determination of dissolved active $\mathrm{Cu}$ (A), dissolved acid extractable $\mathrm{Cu}(\mathrm{B})$, and total acid extractable $\mathrm{Cu}(\mathrm{C})$ in seawater by standard addition method. The concentrations of $\mathrm{Cu}^{2+}$ added are (A) $0,2,4$, and $6 \mathrm{nmol} \mathrm{L}^{-1}$, (B) $0,5,10$, and $15 \mathrm{nmol} \mathrm{L}^{-1}$, and (C) $0,20,40$, and $60 \mathrm{nmol} \mathrm{L}^{-1}$ (from bottom to top). The insets show the corresponding linear regressions respectively. electrochemical response of $\mathrm{Cu}^{2+}$ and the variety of redox potentials of different electroactive substances.

\subsection{Speciation analysis of $\mathrm{Cu}$ in seawater}

The primary purpose of the fabrication of this electrochemical platform based on AuNDs/Nafion/ANE was to investigate the concentrations of different species of $\mathrm{Cu}$ in seawater. Standard addition method was adopted to determine the concentrations of different $\mathrm{Cu}$ species. Fig. $6 \mathrm{~A}$ shows the typical SWASV curves of the directly filtered seawater (aliquot 1 ), and the inset shows the corresponding linear regression equation. It should be noted that the current response obtained without addition of $\mathrm{Cu}^{2+}$ in this aliquot was much small, and baseline correction was used for each recorded voltammogram. When dealing with the baseline correction, the voltammogram obtained without accumulation process was used as the background, and the voltammograms obtained with successive addition of $\mathrm{Cu}^{2+}$ were presented after the background subtraction. The dissolved active $\mathrm{Cu}$ concentration has been calculated to be $1.90 \mathrm{nmol} \mathrm{L}^{-1}$. It should be noted that it is very difficult to achieve the determination of dissolved active $\mathrm{Cu}$ in seawater due to its low concentration and complex matrix interference. Thanks to the excellent performance for $\mathrm{Cu}^{2+}$ detection of the AuNDs/Nafion/ANE, the dissolved active $\mathrm{Cu}$ in seawater can be determined directly without any pre-concentration treatments or any additional reagents. Similarly, Fig. $6 \mathrm{~B}$ and $\mathrm{C}$ determined the dissolved acid extractable and total extractable $\mathrm{Cu}$ concentrations. Considering that the current responses obtained without addition of $\mathrm{Cu}^{2+}$ were remarkable in Fig. 6B and C, there was no need to deal with the background signals. All results of different $\mathrm{Cu}$ species of the seawater samples collected from the Sishili Bay were listed in Table 2. The results indicated that our proposed AuNDs/Nafion/ANE was reliable and suitable for the determination of the dissolved active, dissolved acid extractable, and total acid extractable $\mathrm{Cu}$ in seawater.

\section{Conclusions}

In summary, a novel and efficient needle-shaped electrode functionalized with AuNDs/Nafion was fabricated for the ultrasensitive speciation analysis of $\mathrm{Cu}$ in seawater samples collected from Sishili Bay, Northern Yellow Sea, China. Thanks to the combined effects of the unique needle-shaped structure of ANE, the excellent electrochemical properties of AuNDs and the specific preconcentration ability of Nafion, the AuNDs/Nafion/ANE showed excellent performance for the electrochemical determination of $\mathrm{Cu}^{2+}$ in seawater. The schematic of voltammetric determination of $\mathrm{Cu}^{2+}$ on the so-designed functional needle-shaped electrode was explained as the adsorption-catalysis model. The dissolved active, dissolved acid extractable and total acid extractable $\mathrm{Cu}$ concentrations were determined directly at the AuNDs/Nafion/ANE via SWASV. This so-fabricated AuNDs/Nafion/ANE has several advantages, such as easy fabrication procedure, high sensitivity, excellent repeatability and reproducibility, high storage stability, which can be of great benefit for the speciation analysis of $\mathrm{Cu}$ and other metals in seawater. Furthermore, the speciation and distribution of other

Table 2

Speciation analysis of $\mathrm{Cu}$ at AuNDs/Nafion/ANE in seawater samples collected from three different locations across Sishili Bay ( $\mathrm{n}=3$ ).

\begin{tabular}{|c|c|c|c|c|}
\hline Seawater samples & Dissolved active $\mathrm{Cu} / \mathrm{nmol} \mathrm{L}^{-1}$ & Dissolved acid extractable $\mathrm{Cu} / \mathrm{nmol} \mathrm{L}^{-1}$ & Total acid extractable $\mathrm{Cu} / \mathrm{nmol} \mathrm{L}^{-1}$ & Ratio of dissolved active $\mathrm{Cu}$ \\
\hline Location 1 & $1.90 \pm 0.05$ & $5.76 \pm 0.17$ & $25.83 \pm 0.78$ & $7.4 \pm 0.4 \%$ \\
\hline Location 2 & $0.99 \pm 0.04$ & $12.60 \pm 0.34$ & $45.29 \pm 1.37$ & $2.2 \pm 0.2 \%$ \\
\hline Location 3 & $1.92 \pm 0.06$ & $6.39 \pm 0.18$ & $36.42 \pm 1.12$ & $5.3 \pm 0.3 \%$ \\
\hline
\end{tabular}


metal elements in different water samples can be assessed by the functional needle-shaped electrode as well.

\section{Acknowledgments}

This work was financially supported by the Youth Innovation Promotion Association (2011170), the Key Research and Development Plan of Shandong Province (2017GHY215002), the Key Research and Development Plan of Yantai City (2017ZH096). We also would like to acknowledge the MogoEdit for their language editing service.

\section{Appendix A. Supplementary data}

Supplementary data to this article can be found online at https://doi.org/10.1016/j.electacta.2018.08.097.

\section{References}

[1] S. Maity, S.K. Sahu, G.G. Pandit, Determination of traces of Pb, Cu and Cd in seawater around Thane Creek by anodic stripping voltammetry method, Bull. Environ. Contam. Toxicol. 98 (2017) 534-538.

[2] G. Zhang, D. Liu, H. Wu, L. Chen, Q. Han, Heavy metal contamination in the marine organisms in Yantai coast, northern Yellow Sea of China, Ecotoxicology 21 (2012) 1726-1733.

[3] C.N. Fung, J.C.W. Lam, G.J. Zheng, D.W. Connell, I. Monirith, S. Tanabe, B.J. Richardson, P.K.S. Lam, Mussel-based monitoring of trace metal and organic contaminants along the east coast of China using Perna viridis and Mytilus edulis, Environ. Pollut. 127 (2004) 203-216.

[4] M. Araya, M. Olivares, F. Pizarro, A. Llanos, G. Figueroa, R. Uauy, Communitybased randomized double-blind study of gastrointestinal effects and copper exposure in drinking water, Environ. Health Perspect. 112 (2004) 1068-1073.

[5] G.J. Brewer, Risks of copper and iron toxicity during aging in humans, Chem. Res. Toxicol. 23 (2010) 319-326.

[6] M. Liu, D. Pan, W. Pan, Y. Zhu, X. Hu, H. Han, C. Wang, D. Shen, In-situ synthesis of reduced graphene oxide/gold nanoparticles modified electrode for speciation analysis of copper in seawater, Talanta 174 (2017) 500-506.

[7] A. Milne, W. Landing, M. Bizimis, P. Morton, Determination of Mn, Fe, Co, Ni, $\mathrm{Cu}, \mathrm{Zn}, \mathrm{Cd}$ and $\mathrm{Pb}$ in seawater using high resolution magnetic sector inductively coupled mass spectrometry (HR-ICP-MS), Anal. Chim. Acta 665 (2010) 200-207.

[8] S. Huang, Z. Wang, Application of anodic stripping voltammetry to predict the bioavailable/toxic concentration of $\mathrm{Cu}$ in natural water, Appl. Geochem. 18 (2003) 1215-1223.

[9] Z. Wang, Z. Cui, Determination of arsenic species in solid matrices utilizing supercritical fluid extraction coupled with gas chromatography after derivatization with thioglycolic acid n-butyl ester, J. Separ. Sci. 39 (2016) 4568-4576.

[10] M.C. Henry, Supercritical fluid chromatography, pressurized liquid extraction, and supercritical fluid extraction, Anal. Chem. 78 (2006) 3909-3915.

[11] P. Kuban, A.R. Timerbaev, Inorganic analysis using CE: advanced methodologies to face old challenges, Electrophoresis 35 (2014) 225-233.

[12] D.R.G. Ribeiro, H. Faccin, T.R.D. Molin, L.M. de Carvalho, L.L. Amado, Metal and metalloid distribution in different environmental compartments of the middle Xingu River in the Amazon, Brazil, Sci. Total Environ. 605-606 (2017) 66-74.

[13] L. Vidal, S.G. Silva, A. Canals, J.A. Nobrega, Tungsten coil atomic emission spectrometry combined with dispersive liquid-liquid microextraction: a synergistic association for chromium determination in water samples, Talanta 148 (2016) 602-608.

[14] R. Zhang, M. Peng, C. Zheng, K. Xu, X. Hou, Application of flow injection-green chemical vapor generation-atomic fluorescence spectrometry to ultrasensitive mercury speciation analysis of water and biological samples, Microchem. J. 127 (2016) 62-67.

[15] X. Zhu, R. Zhang, S. Liu, Y. Wu, Z. Jiang, J. Zhang, Seasonal distribution of dissolved iron in the surface water of Sanggou Bay, a typical aquaculture area in China, Mar. Chem. 189 (2017) 1-9.

[16] A. Afkhami, M. Soltani-Shahrivar, H. Ghaedi, T. Madrakian, Construction of modified carbon paste electrode for highly sensitive simultaneous electrochemical determination of trace amounts of copper (II) and cadmium (II), Electroanalysis 28 (2016) 296-303.

[17] A. Annibaldi, S. Illuminati, C. Truzzi, G. Scarponi, SWASV speciation of Cd, Pb and $\mathrm{Cu}$ for the determination of seawater contamination in the area of the Nicole shipwreck (Ancona coast, Central Adriatic Sea), Mar. Pollut. Bull. 62 (2011) 2813-2821.

[18] A. Annibaldi, S. Illuminati, C. Truzzi, G. Libani, G. Scarponi, Pb, Cu and Cd distribution in five estuary systems of Marche, central Italy, Mar. Pollut. Bull.
96 (2015) 441-449.

[19] M.D. Granado-Castro, M.J. Casanueva-Marenco, M.D. Galindo-Riaño, H. El Mai, M. Díaz-de-Alba, A separation and preconcentration process for metal speciation using a liquid membrane: a case study for iron speciation in seawater Mar. Chem. 198 (2018) 56-63.

[20] J.M. Kim, O. Baars, F.M.M. Morel, The effect of acidification on the bioavailability and electrochemical lability of zinc in seawater, Philos. Trans. A Math. Phys. Eng. Sci. 374 (2016).

[21] T. Nagai, A. Imai, K. Matsushige, K. Yokoi, T. Fukushima, Voltammetric determination of dissolved iron and its speciation in freshwater, Limnology 5 (2004) 7-94.

[22] L. Tang, D. Du, F. Yang, Z. Liang, Y. Ning, H. Wang, G. Zhang, Preparation of graphene-modified acupuncture needle and its application in detecting neurotransmitters, Sci. Rep. 5 (2015) 11627.

[23] X. Niu, Z. Wen, X. Li, W. Zhao, X. Li, Y. Huang, Q. Li, G. Li, W. Sun, Fabrication of graphene and gold nanoparticle modified acupuncture needle electrode and its application in rutin analysis, Sens. Actuators B: Chem. 255 (2018) 471-477.

[24] L. Tang, Y. Li, H. Xie, Q. Shu, F. Yang, Y. Liu, F. Liang, H. Wang, W. Huang, G. Zhang, A sensitive acupuncture needle microsensor for real-time monitoring of nitric oxide in acupoints of rats, Sci. Rep. 7 (2017) 6446.

[25] Y. Li, L. Tang, Y. Ning, Q. Shu, F. Liang, H. Wang, G. Zhang, In vivo monitoring of serotonin by nanomaterial functionalized acupuncture needle, Sci. Rep. 6 (2016) 28018.

[26] H. Han, D. Pan, C. Wang, R. Zhu, Controlled synthesis of dendritic gold nanostructures by graphene oxide and their morphology-dependent performance for iron detection in coastal waters, RSC Adv. 7 (2017) 15833-15841.

[27] F. Li, D. Pan, M. Lin, H. Han, X. Hu, O. Kang, Electrochemical determination of iron in coastal waters based on ionic liquid-reduced graphene oxide supported gold nanodendrites, Electrochim. Acta 176 (2015) 548-554.

[28] X. Xu, J. Jia, X. Yang, S. Dong, A templateless, surfactantless, simple electrochemical route to a dendritic gold nanostructure and its application to oxygen reduction, Langmuir 26 (2010) 7627-7631.

[29] M. Lin, D. Pan, X. Hu, H. Han, F. Li, Titanium carbide nanoparticles/ionexchange polymer-based sensor for catalytic stripping determination of trace iron in coastal waters, Sens. Actuators B: Chem. 219 (2015) 164-170.

[30] J. Wei, S.S. Li, Z. Guo, X. Chen, J.H. Liu, X.J. Huang, Adsorbent assisted in situ electrocatalysis: an ultra-sensitive detection of $\mathrm{As}(\mathrm{III})$ in water at $\mathrm{Fe}_{3} \mathrm{O}_{4}$ nanosphere densely decorated with Au nanoparticles, Anal. Chem. 88 (2016) 1154-1161.

[31] M. Yang, X. Chen, T.J. Jiang, Z. Guo, J.H. Liu, X.J. Huang, Electrochemical detection of trace arsenic(III) by nanocomposite of nanorod-Like $\alpha-\mathrm{MnO}_{2}$ decorated with $\sim 5 \mathrm{~nm}$ Au nanoparticles: considering the change of arsenic speciation, Anal. Chem. 88 (2016) 9720-9728.

[32] L.S.G. Teixeira, E.S. Santos, L.S. Nunes, Determination of copper, iron, nickel and zinc in ethanol fuel by energy dispersive X-ray fluorescence after preconcentration on chromatography paper, Anal. Chim. Acta 722 (2012) 29-33.

[33] M.F.d. Oliveira, V.R. Balbo, J.F.d. Andrade, A.A. Saczk, L.L. Okumura N.R. Stradiotto, Quantitative assay of copper, iron, nickel, and zinc in fue ethanol samples by flame atomic absorption spectrometry, Chem. Technol. Fuels Oils 44 (2008) 430-434.

[34] L.N. Santos, J.A.G. Neto, N.M. Caldas, Simultaneous determination of $\mathrm{Cu}$ and $\mathrm{Pb}$ in fuel ethanol by graphite furnace AAS using tungsten permanent modifier with co-injection of Ir, Fuel 99 (2012) 9-12.

[35] W. Song, L. Zhang, L. Shi, D.-W. Li, Y. Li, Y.-T. Long, Simultaneous determination of cadmium(II), lead(II) and copper(II) by using a screen-printed electrode modified with mercury nano-droplets, Microchim. Acta 169 (2010) 321-326.

[36] J. Wang, C. Bian, J. Tong, J. Sun, S. Xia, Simultaneous detection of copper, lead and zinc on tin film/gold nanoparticles/gold microelectrode by square wave stripping voltammetry, Electroanalysis 24 (2012) 1783-1790.

[37] P.K. Sahoo, B. Panigrahy, S. Sahoo, A.K. Satpati, D. Li, D. Bahadur, In situ synthesis and properties of reduced graphene oxide/Bi nanocomposites: as an electroactive material for analysis of heavy metals, Biosens. Bioelectron. 43 (2013) 293-296.

[38] S. Muralikrishna, K. Sureshkumar, T.S. Varley, D.H. Nagaraju, T. Ramakrishnappa, In situ reduction and functionalization of graphene oxide with L-cysteine for simultaneous electrochemical determination of cadmiu$\mathrm{m}(\mathrm{II})$, lead(II), copper(II), and mercury(II) ions, Anal. Meth. 6 (2014) $8698-8705$.

[39] J.J. Silva, L.L. Paim, N.R. Stradiotto, Simultaneous Determination of iron and copper in ethanol fuel using nafion/carbon nanotubes electrode, Electroanalysis 226 (2014) 1794-1800.

[40] Y. Zhang, M. Qi, G. Liu, C-C bonding of graphene oxide on 4-aminophenyl modified gold electrodes towards simultaneous detection of heavy metal ions, Electroanalysis 27 (2015) 1110-1118.

[41] D. Wang, F. Zhang, J. Tang, Sodium alginate decorated carbon nanotubesgraphene composite aerogel for heavy metal ions detection, Electrochemistry 83 (2015) 84-90.

[42] P. Salaün, C.M.G. van den Berg, Voltammetric detection of mercury and copper in seawater using a gold microwire electrode, Anal. Chem. 78 (2006) 5052-5060. 